\title{
Customer focused science and knowledge management for sustainability in New South Wales, Australia
}

\author{
G.K. Summerell ${ }^{1}$, J. Leys ${ }^{1}$ and K. Wilson ${ }^{1}$ \\ Affiliation: Office of Environment and Heritage, NSW Government \\ Email: gregory.summerell@environment.nsw.gov.au
}

\begin{abstract}
The New South Wales (Australia) State Government's direction is set through its 'NSW 2021 : A plan to make NSW number one' ten year strategic plan. Key to the government's reforms is the objective to increase the devolution of decision making to the community by providing open access to data, information and services via transparent processes. For the NSW Office of Environment and Heritage (OEH), this is achieved through 'The Open OEH' program. The vision is to make OEH data and services open, available, accessible and useful to the community anywhere and anytime. This requires customer focused delivery that may depend on cross agency collaborations to set and deliver priority outcomes.
\end{abstract}

Science within state government improves objective decision making at all levels and provides a lens through which often competing perspectives and demands from multiple customers may be better viewed and considered. The expectation is that science will 'bring to the table' and illuminate rigorous and transparent data and information on relevant issues and matters. OEH is seeking to better fulfil these expectations through its corporate emphasis on engaging customers. Understanding customer values is emerging as an important element in project management. A customer focus will progressively inform strategic priority setting for end to end project delivery of OEH science and knowledge management.

State government science does not duplicate that of other recognised science providers. Science within Federal Agencies and Universities is more exploratory in nature whereas state government science is directed research, often drawing information from imperfect/incomplete knowledge. This knowledge is enhanced through participatory end user engagement, which allows for understanding of the data limitations and assumptions. Critical to this process is the concept of scientist social capital; that is, the benefits that arise from the science practitioner's connections, reputation, status and relationships. Paramount to success is developing and maintaining trust with an often diverse customer base.

In the OEH the Science Division has undergone a major restructure to respond to the needs of NSW 2021. The new Ecosystem Management Science (EMS) branch consists of cross functional teams designed to deliver products and services to customers and colleagues undertaking policy and program design and delivery. The teams in the branch are headed by recognised scientific leaders who run programs using collective decision making. This seeks to optimise benefits from the science social capital of their connections, reputations and knowledge. It also enables them and their teams to work within a matrix management model to provide rapid and responsive science solutions while working towards long term strategic science program goals. There is a strong interdependency among all the EMS teams and this encourages interactions between individuals making possible a broad canvassing of ideas and knowledge.

An important feature of the EMS branch is that its six teams are orientated on outcomes rather than science disciplines. This acts to further facilitate improved access to science and knowledge across teams and greater sharing of project components. To enhance knowledge creation and flow to customers, a dedicated science Knowledge Service Team has been created to instill rigor in knowledge management and thus directly contribute to Open OEH. This team will be strongly supported by an Evaluation Team that uses modeling and decision support systems. These systems will provide transparent, repeatable forecasting and scenario analysis capabilities. Clear two-way communication, will increase customer engagement, understanding, evidence-based decision making and action. Ultimately this will lead to better informed and more transparent discussions about ecosystem management including options for trade-offs and multiple co-benefits from government decisions and community investment. This will boost prosperity and sustainability by empowering community and government decision makers to improve ecosystem services and better sustain landscape and community productivity and function.

Keywords: Ecosystem management, knowledge management, science communication, NSW 2021 


\section{INTRODUCTION}

Ecosystems are comprised of biotic (flora, fauna and humans), and abiotic components (air, water, soils and landscapes) and ecological processes that operate among and within these components. All ecosystems provide a range of useful resources and services, which include clean air and water, healthy soils, productive landscapes, resilient vegetation and fauna. Ecosystems can be impacted by a diverse array of external threats and pressures, including biophysical, social, economic and cultural. Therefore, the challenge for ecosystem management science is: (i) to understand the interactions between components, processes, threats and pressures, and the delivery of ecosystem services, and (ii) to advocate and assist management actions based on rigorous science.

NSW 2021 (NSW Government, 2011) is the strategic plan for the NSW government that guides its business and decision making. One of its core areas is "Strengthen our local environments and communities" via a process of devolving decision making to local levels. NSW 2021 sees decision makers as customers that government aims to serve and describes how government will assist customers in their decision making though more open access to data and information. The Office of Environment and Heritage (OEH) plans to achieve greater accessibility to information through the Open OEH program. The vision: to make OEH data and services open, available, accessible and useful to the community anywhere and anytime.

However before decisions can be made, people need to understand the cultural, social, economic and environmental interactions. To enable this to occur these four aspects need to be converted into enhanced and available knowledge and then clearly communicated to customers. The challenge is that the interactions are not linear in nature or straight forward due to inherent levels of differing complexity. Customers range from on ground practitioners to policy development. Science uses a systematic approach to achieve science rigor and transparency to service both these customers; however, these two customers have different methods of using data and information. On ground practitioners access a range of information at difference scales, purposes and locations, making decisions to reduce risk and maximise outcomes (Hillman et al 2003, Cullen 1990). Policy objectives tend to respond to a community need and synthesise several disciplines of knowledge (Briggs, 2006) to achieve their outcome. Further complexity is evident when the community's social and economic values are considered, as tradeoffs for desired outcomes may need to occur.

A common example of trade-offs is that relating to land use. To increase economic resilience of a business the strategy is often to increase the capital base of an investment, leading to land development. Concurrently, natural resource and environmental managers look to increase the diversity of habitats and ecosystems. They are seeking to increase the resilience of the environmental base by increasing land occupied by natural assets. Economic and environmental managers are therefore seeking to increase investment in their assets to bring resilience to their corresponding systems. But the challenge is that the objectives of the investments may appear conflicting (Aronson et al. 2007) and hence transparent discussion on alternative solutions or tradeoffs needs to occur.

Therefore to achieve the fundamental goals of NSW 2021 it will be necessary to understand and quantify the social, economic and biophysical ramifications of decisions. Science needs to play a greater role in this decision making through the provision of enhanced knowledge to better underpin rational and transparent decisions. Clarifying and enabling multiple benefits to harmonise change is a critical component. State government science needs to comprehensively embrace this if it is to increase synergies between disciplines and customer groups and bring improved understanding of issues for decision making.

This paper describes how the unique contribution of State Government Science to State goals might be enhanced via new customer focused science supported through knowledge management and modeling frameworks. This framework is strongly guided by a strategic departmental Knowledge Strategy (http://www.environment.nsw.gov.au/knowledgestrategy/index.htm) which has underpinned the major restructure of the Science Division including the creation of the EMS branch.

\section{ECOSYSTEM MANAGEMENT SCIENCE}

Science is delivered through a variety of agencies in NSW. CSIRO has a distinct role as the nation's leading large scale, multidisciplinary, mission-directed science and technology organization and their customers tend to be industry and government agencies. Universities have responsibility to promote excellence in research and education by emphasising the mutual dependence of these activities at the highest levels of learning and their customers tend to be students, industry and government agencies (Figure 1). State science connects these focused science organizations with policy and on-ground practitioners. It is in essence "science integrator" that connects state science outputs with outputs from others to achieve specific NSW outcomes. 
This is done by providing a bridge between the research of CSIRO and Universities, and aims to inspire a more collaborative approach to science. It delivers to state customers including the government, its agencies and diverse business, industry and community interests. In many ways state agency research is focused on the provision of information to its customers derived from all sources: CSIRO, Universities, other agencies and communities (Figure 2).

To meet the challenges and enable communities and government to make improved decisions two actions have been undertaken: 1) the development of the OEH Knowledge Strategy (described later); and, 2) the development of a new branch called Ecosystem Management Science (EMS) within the OEH to address the landscape management and biodiversity components of the Knowledge Strategy.

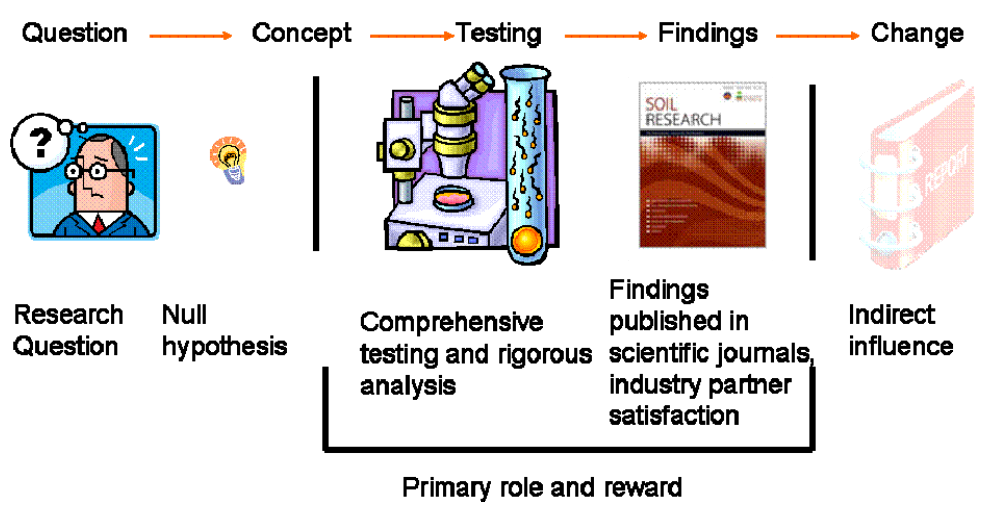

Figure 1. Science in CSIRO and Universities with respect to on-ground influence in NSW.

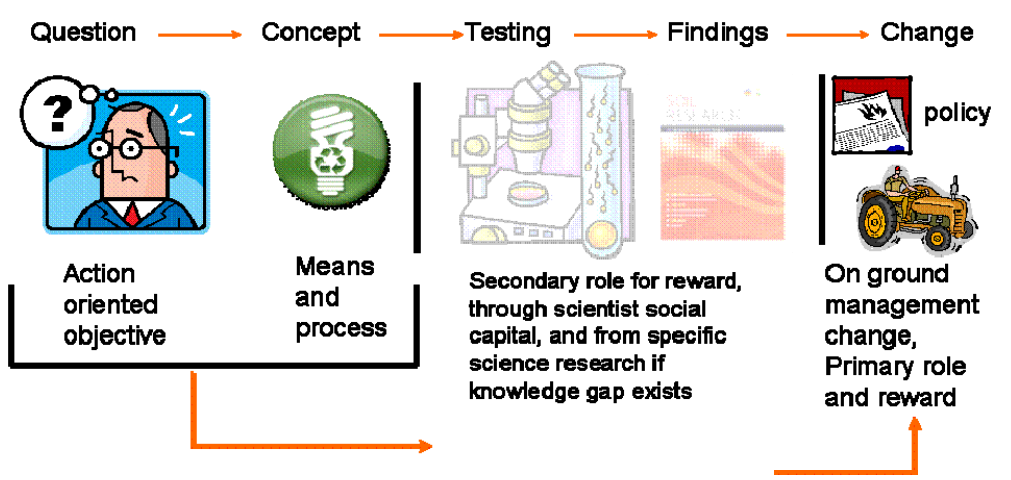

Figure 2. Science in NSW state government with respect to direct influence on policy and on-ground management change. (Note: Scientist social capital refers to their experience and networks).

Due to the complex nature of issues considered by communities and government at all levels with regard to the environment and natural resource management, the EMS branch is very interdisciplinary. Scientists have been drawn from biodiversity, landscape, hydrology, environmental modelling, cultural heritage and social science. The EMS structure aims to directly forge interdisciplinary links using a matrix management approach and tools from modelling and decision support frameworks to enable conversations and learning. Six teams have been established (see 2.3 below) which are not organised by science discipline but by their science outcome. Removing the discipline boundaries has been a common goal to reduce friction between disciplines and is an ongoing challenge (Bella and Williamson 1986; Rodgers 2006 and Cullen, 1990).

Each of the six teams has a senior team leader who built their respective teams from scratch by identifying the skills and competencies required to meet the strategic needs of OEH. The new positions in EMS were then filled through a merit based selection process drawing employees from both within and external to the organization, with each team comprising 6-8 permanent employees. This was unlike previous reorganizations where the skills of the people were fitted to a new structure rather than the new direction. This new team building was an intentional key psychological pathway for change adoption. It has enabled staff to embrace the significant organisational cultural shift underpinning the new EMS branch. This approach has provided a setting whereby each staff member is starting with new challenges and opportunities.

Yang et. al. (2013) described the above process as being key to quickly maximizing the social acceptance of staff to large cultural change. They also note the efficiency of small teams, as new communication and people connection processes are developed. Due to the small size of the teams, compared to previous larger 
structures in the Science Division, the EMS branch will have reduced transaction costs. Yang et. al. also discuss how small groups reduce the likelihood of individuals focusing on their own choice of outcomes that may not align to the group's direction, and using the group infrastructure without contributing to group processes or outcomes. The disadvantage of small groups is that there are minimal resources to deploy across changing work programs.

The senior team leaders are recognised science leaders with established standing and peer recognition. This is described as the scientist social capital within this paper. The staff in these positions were recruited for the scientist social capital they have developed, along with their skills in science leadership. Collectively they will guide the branch direction and resources with joint planning and decision making similar to the interactions akin to a 'board'. They will have individual accountability and responsibility for major programs. To make sure the senior team leaders are not over burdened with administration / management duties and can maintain their science standing, each team is constrained to 6 to 10 permanent staff, (with potentially 2 to 3 temporary staff). Through the processes, senior team leaders will be able to stimulate and challenge each other on decisions, develop mutual understanding and learn more about the range of disciplines and gain ownership of the outcomes the branch will deliver. Team leaders will mitigate against the resource limitations of small teams by matrix management of resources from the branch; and capitalizing on their science social capital to draw in research funds. They will be able to expand resources using the established confidence and trust earned from previous customer investments.

Being challenged and continuing to learn are important stimuli for scientists and these criteria tend to be harder to instill within higher levels of science management under traditional government operational structures. The EMS branch structure will stimulate all its scientists (including the senior team leaders) with new challenges and learning, and collectively build the total scientist social capital base. To achieve this, the branch has adopted the following three basic operational principles:

\subsection{Strong focus on customers and knowledge management}

Natural resource and environmental management is interdisciplinary by nature. For knowledge building to occur and trust to be forged, many fundamental issues need to be overcome. Issues identified are the lack of clear problem definition, lack of conceptual frameworks and confusion over the role of science in a program (Chapple et al. 2011). When a customer engages with the EMS branch the relevant senior team leaders and Knowledge Service Team will come together and work directly with the customer to clearly formulate the questions, build mutually agreed conceptual frameworks and processes for the project.

Where trade-offs are required, various decision scenarios will be evaluated and documented in a transparent way, often using modelling, decision support and business frameworks in a planning context. The branch has three facilitation positions within the Knowledge Services Team that will enable and promote an open discussion of a project and clear communication of arising collective decisions. While facilitators will acknowledge people's emotions and ideologies they should not allow these to dominate dialogue, thereby allowing a greater range of opinions to be expressed and evaluated. The key aim is to clearly define the research question that will inform the customers' needs, develop realistic and agreed expectations with the customer and proactively interact so that all necessary team members in EMS can contribute. By having the senior team leaders active across multiple programs, this will enhance communication and collective decision making through this structured process of project planning, commissioning, delivery and review.

\subsection{Strategic priorities, leading to knowledge creation, direction and common messaging for outcome delivery}

The strategic direction of EMS is provided through the Knowledge Strategy which identifies priority knowledge needs for $\mathrm{OEH}$ to deliver to meet policy, program and legislative needs and relevant goals and targets in NSW 2021. The knowledge includes support for on-ground regional operations and national park management. The Knowledge Strategy has six themes: biodiversity; climate change impacts and adaptation; coastal, estuarine and marine environments; landscape management; pollution; and water and wetlands. The Knowledge Strategy was developed by policy and program managers, scientific experts and planners from across OEH, including national parks. Within EMS the senior team leaders will create consensus on branch priorities that will contribute to the Knowledge Strategy, particularly the Biodiversity and Landscape Management themes.

Once projects are commissioned, scientific rigor will be the focus of the collective guidance. Final outcomes / recommendations will be developed with a consistent message. The common science habit of overloading the customer with information will be avoided by developing the consistent messaging through the support of 
the Knowledge Services Team. These will also jointly act to preclude the presentation of a range of conflicting options in a manner that can be misinterpreted by customers as 'there is no answer or information'. This often leads to outright rejection of recommendations due to the customer being confused by the debate rather than understanding the key information being presented. Clear consistent science messages with transparent methods and data that support them will evolve a more robust and trusted relationship with customers, empowering them to make more and better decisions.

\subsection{The matrix model, business processes and teams}

The teams in EMS are arranged by outcomes and are designed to work within a matrix management model. The key to success will be the linkages and operational interactions that develop between the teams. To exemplify how business processes are intended to work within the model, a generic response to clients strategic needs will be considered. Following identification of the knowledge need through the OEH knowledge strategy, initial discussions about a given project would be initially scoped by the Knowledge Service and Evaluation teams in close continuing co-operation with the customer and the key team involved in implementation. This process ensures focused discussion to facilitate ultimate agreement. In most cases this would identify how and in what form project products and findings are to be used to support the delivery of project outcomes. Resources of each 'relevant team' are then deployed. For clear and common messaging, joint identification, understanding and ownership of end products and intended outcomes with customers are essential. When looking at the management tools used to enact change, the role is either to conserve (maintain or preserve an asset) or restore (rehabilitate an asset). The funding options and objectives for these two outcome actions are very different in terms of the resources required for implementation (Summerell, 2011) which is why they are separately represented within EMS.

The Knowledge Services Team. This team's role is to “Help people make better decisions using enhanced knowledge in forms that can be readily used wherever and whenever it is needed". The Knowledge Service Team intent is to support the development and implementation of the Biodiversity and Landscape Management themes of the OEH Knowledge Strategy which are the high level strategic documents most relevant to EMS. The team will engage with people to promote and empower customers and communities to enhance the productive use of their land and deliver ecosystem services through sustainable land management. As a business procedure this team will also use program performance measures to quantify the impact of EMS.

The Evaluation Team will "quantify current impacts and predict future impacts from threats and pressures on terrestrial ecosystems (e.g. changes in climate, land use, and land management), using data synthesis and brokering, decision support tools, modelling and impact assessments". This team will provide information that will enable customers to evaluate current and future environmental management actions and challenges. This will be achieved via evaluation of data and information gathered by the Knowledge Services, Assessment, Processes and Implementation Teams on current and potential impact of changes in climate, land use and land management practices on terrestrial ecosystems and landscapes. This modelling group is critical within the knowledge creation and communication pathways as they will provide the transparent, repeatable and objective framework for project implementation and delivery.

The Assessment Team will "maintain and promptly provide accessible, understandable and usable NSW soil and land data and information which is fit for purpose and supports sustainable land use and natural resource management and sound decision making". This Team will provide a range of key ecological data and information to other EMS teams, OEH Divisions, external customers and communities which will be critical to sound planning and decision making. It will also provide key inputs to evidence-based decision making at all levels of government and generally to businesses, industries and communities.

The Process Team will “analyse ecological, land use and land management data to identify drivers of ecological systems and derive understanding of how the systems operate so as to provide insight on how to manage the systems for desired outcomes". Successful management and conservation of species, ecological communities and ecosystems depends on an understanding of the processes that are essential for their continued persistence. This will range from species interactions, key life history components (recruitment, dispersal, survival), disturbance regimes (fire, water, storms etc) to landscape scale connectivity and refugia. The challenge is to be able to maintain the resilience of species, ecological communities and ecosystems under the range of existing threats, along with the exacerbation of those threats and the introduction of novel threats (such as pathogens, increased heat stress/impact etc) in a changing climate.

The Conservation Team will "conserve and maintain the ecosystems in NSW by maintaining and improving resilience capacity of ecosystems and the people who manage the land”. The Restoration Team 
will "rehabilitate terrestrial ecosystems that have been degraded, by restoring the resilience capacity of ecosystems and the people who manage the land". Successful management will be achieved by developing and implementing management strategies based on the understanding of the systems, as derived from the collective science outcomes from the EMS teams in consultation with customers.

Project delivery and knowledge creation within EMS is conceptualized in Figure 3. As outlined previously, the five knowledge-based, outcome-themed Teams work with the Knowledge Services Team to develop the scope of the project based on clear and agreed customer expectations. Project planning and development then takes place in continuing close co-operation with customers using the modelling and decision support frameworks to capture and communicate the complex scientific interactions and quantify the tradeoffs and benefits. Previous discipline-based science structures are represented at the application and outcomes flow of the diagram in grey. It is hypothesized that the new EMS structure through the three operational principles will increase ecosystem outcomes. This is diagrammatically conceptualized by the expansion of the knowledge created in green. The challenge for the EMS branch will be measuring this difference. Newly arising impacts from inter-disciplinary knowledge and understanding is shown in dark green. Even more challenging, but potentially highly rewarding is for the EMS teams and processes to transcend and become transdisciplinary. Characteristics of this transcendence are outlined by Guthrie et. al. (2003) who argue that arising new levels of participation and creativity further improve ecosystem benefit outcomes.

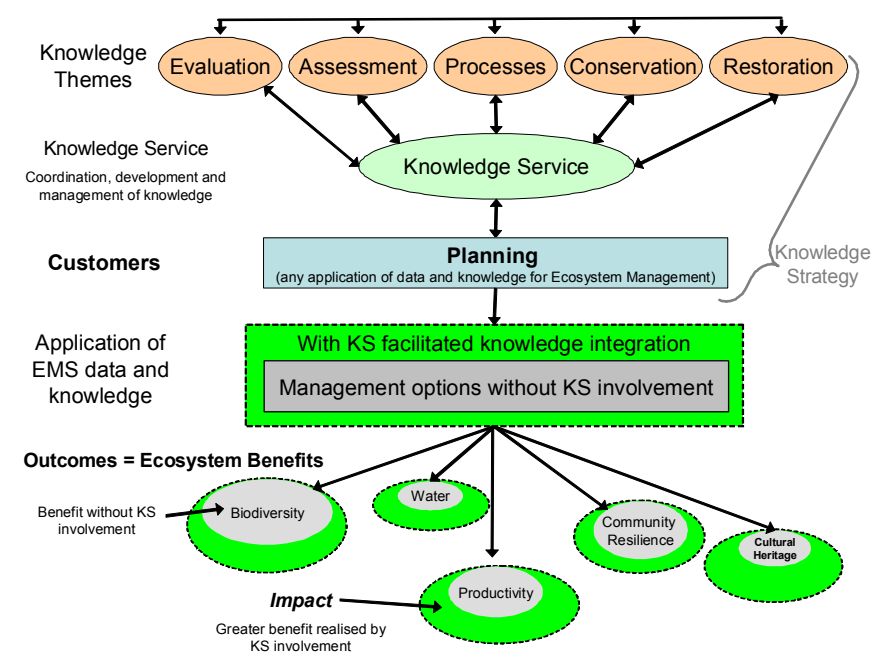

Figure 3. The EMS framework showing project design and information flow of the EMS branch with grey areas representing the impact of the science without knowledge management.

\section{CONCLUSIONS}

To enhance the effectiveness of State Government science, OEH has developed a Knowledge Strategy that identifies priority knowledge needs for $\mathrm{OEH}$ to meet policy, program and legislative needs and relevant goals and targets within NSW 2021. The EMS branch has been established around a number of innovations. It has been designed as a knowledge management response to the OEH Knowledge Strategy (specifically Biodiversity and Landscape themes) and embraces customer participation throughout project conception, development, delivery and review. Knowledge exchange processes are complemented with modelling frameworks to communicate complex, inter-disciplinary messages and trade-off scenarios are implemented as operational concepts of the branch. This approach is a major change to the way traditional science has been implemented. To maximize the benefits of the pioneering framework three principles are developed.

1) Strong focus on customers and knowledge management: Scientist social capital has been recognized within the branch and will continue to develop through the empowerment of scientists as leaders rather than as managers only. This gives prominence to science excellence as a core value of the branch and allows the combined scientist social capital to influence larger customer groups. By having the teams outcome, rather than discipline orientated, the discipline silos are removed. This allows cross fertilization of contributions to projects and better addresses the integrated and complex nature of delivering environmental and natural resource management programs and projects.

2) Strategic priorities: Within the branch there are two sources of key funds. Those that are internal and those that are external. The use of these funds will be controlled by priorities set in the OEH Knowledge 
Strategy. The internal branch funds will be distributed by the senior team leaders so that the control and distribution of funds is both strategically and transparently allocated. For external funds the aim is to expand the capital and operational base by utilising the social capital of the scientists to attract funds that contribute to longer term strategic directions of $\mathrm{OEH}$.

3) Matrix management and business process: Branch science and knowledge is a key traditional strength of the group. By structuring on outcomes the focus is on the delivery mechanisms of the science disciplines. This will be managed through the senior team leaders and the dedicated Knowledge Services Team, coupled with decision support and strategic modeling interfaces. Together these will enable two -way transparent communication and project development.

State government science uniquely contributes to State goals. The development and adoption of the OEH Knowledge Strategy to guide science direction and the implementation of the new EMS framework will directly contribute to the Open $\mathrm{OEH}$ vision. This will better enable improved evidence-based decision making to boost prosperity and sustainability consistent with NSW 2021. Enhanced knowledge management and customer engagement by EMS will empower community and government decision makers to improve ecosystem services and better sustain landscape productivity and function.

\section{ACKNOWLEDGMENTS}

The authors would like to thank the Senior Team Leaders, Knowledge Services Team staff of EMS and Jo White for their contributions to develop the branch conceptual model and its implementation.

\section{REFERENCES}

Aronson, J, Milton S and J.N, Blignaunt (1997) Restoring Natural Capital: Science, Business, and practice. Society for ecological restoration international, ISLANDpress Washington, Covelo, London. ISBN 13:978-159726-076-3.

Bella, D.A and Williamson, K.J (1986). Conflicts in interdisciplinary research. Interdisciplinary Analysis and research, 6, 347-354.

Briggs, S.V (2006). Integrating policy and science in natural resources: why so difficult? Ecological Management and Restoration 7, 37-39.

Cullen, P. (1990). The turbulent boundary between water science and water management, Freshwater Biology. 24, 201-209.

Chapple, R., Ramp, D., Bradstock, R, Kingsford, R., Merson, J., Auld, T., Fleming, P and Mulley, R. (2011). Integrating science into management of ecosystems in the Greater Blue Mountains. Environmental Management 48, 659-674.

Guthrie, A.C.M., Attwater, R., Booth, C.A., Collins, A.P. and McPherson, R.G. (2003) A Transdisciplinary Approach to Pursuing Ecosystem Health in a Degraded Catchment. Conference Proceedings from Transdisciplinary and Ecosystem Health Conference Newcastle University July 2003.

Hillman, M., Aplin, G., and Brierley, G. (2003). The Importance of process in Ecosystem Management: Lessons from the Lachlan Catchment NSW, Australia. J. Env. Planning and Management 46, 219-237.

NSW Government (2011). NSW 2021.NSW Department of Premier and Cabinet. http://www.2021.nsw.gov.au/sites/default/files/NSW2021_WEB\%20VERSION.pdf

Rodgers, K. (2006). The real river management challenge: integrating scientists. River Research and Applications 22, 269-280.

Summerell G.K., Barrett, T., Grieve A.M. Dunn M., Moerkerken L. and Love J (2011). Implementing decision support for natural resource management agencies - the SCaRPA experience. 19th International Congress on Modelling and Simulation, Perth, Australia, 12-16 December 2011 http://mssanz.org.au/modsim2011. pp 2941-2947

Yang, W., Liua W., Viñaa, A., Tuanmua, M, Hea,. G., Dietza T, and Liua J. (2013). Nonlinear effects of group size on collective action and resource outcomes. http://csis.msu.edu/sites/csis.msu.edu/files/PNAS2013-Yang-1301733110.. Edited by Bonnie J. McCay, Rutgers, State University of New Jersey, New Brunswick, NJ. 